\title{
A contribution to the study of negative polarity in GMA welding
}

\author{
Peigang $\mathrm{Li}^{1} \cdot$ Kjell Hurtig ${ }^{2} \cdot$ Mats Högström ${ }^{2} \cdot$ Lars-Erik Svensson $^{2} \cdot$ Americo Scotti $^{2}$
}

Received: 6 June 2017 / Accepted: 8 November 2017 /Published online: 25 November 2017

(C) The Author(s) 2017. This article is an open access publication

\begin{abstract}
Gas metal arc welding (GMAW) using the electrode with negative polarity (DCEN) has been frequently suggested as a potential means of increasing production capacity. The objective of this work was to further study the performance of negative polarity in GMAW of carbon steels. In this project phase, bead-on-plate welds were carried out in flat position to assess the effect of different potential shielding gas compositions on bead geometry, finishing and spattering. The characteristics were compared with DCEP at the same current, but depositing the same volume of material per unit of length (more industrial related comparison). The arc length was kept the same by adjusting voltage to reach shortest arcs, yet with suitable non short-circuiting metal transfer mode. An approach to measure bead convexity was also proposed and assessed. The results showed that DCEN is feasible as a means of increasing GMAW production capacity. However, to become DCEN applicable with GMAW, the results suggest an Ar-based blend with around $6.5 \%$ of $\mathrm{O}_{2}$ is the most appropriate shielding gas, as much as that there is a demand for a standard electronic controlled power source able to work in constant current mode.
\end{abstract}

Keywords Welding · Production $\cdot$ GMAW · Negative polarity $\cdot$ Fusion rate $\cdot$ Weld bead geometry

\section{Americo Scotti}

americo.scotti@hv.se

ESAB AB, Gothenburg, Sweden

2 Production Technology West, Department of Engineering Science, Division of Welding Technology, Högström Väst (University West), Trollhättan, Sweden

\section{Introduction}

Electrode at the negative polarity (DCEN) has not been traditionally applied in gas metal arc welding (GMAW), likely because its expected low performance (low bead wettability on the plate, shallow penetration and high spattering production, yet with faster fusion rate for a given current intensity). A well-respected welding guide [2] stated that "DCEN is seldom used because axial spray transfer is not possible without modifications that have had little commercial acceptance. DCEN has a distinct advantage of high melting rates that cannot be exploited because the transfer is globular". However, new power source technologies and further studies with improved instrumentation have somehow demystified this concept and commercially DCEN is applied nowadays in alternate current (AC) GMAW processes. In AC-GMAW, direct current electrode positive (DCEP) and DCEN are sequentially rotated within one period of current waveform, which means it can take advantage of both positive and negative electrode polarity [8]. The main application of AC GMAW has been to enlarge the gap tolerance in thin plate welding. Arif and Chung [1], for instance, modeled drop sizes, claiming that this was the reason for controlling the key gap-bridging ability of the AC process.

However, an increase of deposition rate has also been notified as related to the contribution of the negative polarity, as demonstrated by Dutra et al. [3] when describing the application in aluminum sailboat construction. Park et al. [13] found that, with the increase in EN ratio, the drop sizes and wire melting rate increased, whereas the heat supplied to the BM decreased. According to Kim and Chung [8], since ACGMAW exhibits characteristics of both DCEP and DCEN at the same time, it is considered as an effective and productive welding process offering advantages such as low heat input to the base metal, high wire melting rate, and stable arc. Even though, one can say that electrode negative has not been fully 
employed, in view of AC application is still considered an "exotic" version of GMAW. Reasons for this could be wide spread not well-succeeded stories and lack of information on the usage of DCEN, which makes end users less confident (and motivated) to use this polarity in production.

Norrish [12] pointed out a long time ago that several attempts had been made in a far past to utilize the high melting rates known to result from electrode negative operation. This author referred to papers from 1955 and 1956 dedicated to this subject, but he recognized that success would have been limited. Norrish also proposed that GMAW improvement towards using DCEN was reached through the shielding gases composition. There is a potential saving capacity of DCEN GMAW if a proper gas composition was used; a cost comparison between the use of GMAW with DCEN shielded with an Ar-based blend $\left(\mathrm{O}_{2}\right.$ and $\left.\mathrm{CO}_{2}\right)$ and the conventional (DCEP $-\mathrm{CO}_{2}$ shielding) over the production of horizontal-vertical fillet weld was presented by Norrish [12]. In the same line, the AWS Welding Handbook [2] claimed that the metal transfer can be improved with steels by adding a minimum of $5 \%$ oxygen to the argon shield (requiring special alloys to compensate for oxidation losses) or by treating the wire to make it thermionic (adding to the cost of the filler metal). Lucas et al. [9] had shown some years earlier the possibility of improving cathode instability when DCEN was used in GMAW of steels. They referred to that instability can occur in this polarity through the climbing of the arc roots up the wire. In addition, they argued that the arc root behavior can be stabilized by the use of an argon-based shielding gas mixture with a sufficiently high oxygen and/ or carbon dioxide content.

Later some researchers confirmed Norrish's [12] and Lucas et al.'s [9] findings and citations. For instance, Souza et al. [20] showed that the metal transfer mode in GMAW DCEN is dependent on the type of shielding gas used, making possible to obtain transfer without repulsive drops (globular and spray). They also demonstrated and concluded that a higher wire melting rate with electrode negative is due to the arc rising up the sides of the wire tip in a search for oxides (for field emission), increasing the efficiency of heat transfer to the wire tip. A consensus is that the shielding gas cannot contain too much oxidizing gases mixed with Ar when using DCEN. Argon with $\mathrm{CO}_{2}$ content greater than $20 \%$ and $\mathrm{CO}_{2}$ only are unsuitable due to excessive spatter formation, per Lucas et al. [9]. Souza et al. [20] considered $18 \% \mathrm{CO}_{2}$ responsible for a great amount of spattering, despite of a better bead geometry.

However, in the referred AWS Welding Handbook [2], it is also said that the deposition rates drop when either oxidizing gas or easy emission element wire addition is applied, eliminating the only real advantage of changing polarity from the conventional DCEP to DCEN. Results from Souza et al. [20] showed that the wire melting rate dropped $17 \%$ when $\mathrm{Ar}+$ $2 \% \mathrm{O}_{2}$ (relatively low oxidizing potential) was replaced by $\mathrm{Ar}+18 \% \mathrm{CO}_{2}$ (relatively higher oxidizing potential) as shielding gas, confirming AWS claim. However, the melting rate was still $29 \%$ higher with DCEN than with DCEP, thus keeping the advantage of higher production with DCEN.

Lucas et al. [9] also observed that metal transfer stability was reached only at high current, for both DCEP and DCEN. Using shield with $\mathrm{Ar}+5 \% \mathrm{O}_{2}$, they observed instabilities (large molten droplets transferring erratically under gravity) when wire feed speed (WFS) was less than $5 \mathrm{~m} / \mathrm{min}$ with DCEP. In practice, the minimum usable speed was approximately $8 \mathrm{~m} / \mathrm{min}(280 \mathrm{~A})$. Above $12 \mathrm{~m} / \mathrm{min}$, the arc and weld pool stability were also impaired due to excessive tapering of the electrode and the gouging of the plate. Therefore, the normal operating range for DC positive welding was 8 to $11 \mathrm{~m} /$ min (280-370 A). On the other hand, in DCEN welding the usable operating range was much larger than with DC positive, which is from 10 to $16 \mathrm{~m} / \mathrm{min}(240-350 \mathrm{~A})$, which could score an advantage for DCEN.

However, per Lucas et al. [9], the operating current (wire feed speed) had a marked effect on the height that the cathode roots climb up the wire above the droplet under formation. With $\mathrm{Ar}+5 \% \mathrm{O}_{2}$ and at a current of $460 \mathrm{~A}$ (wire feed speed at $15 \mathrm{~m} / \mathrm{min}$ ), no arc wandering was observed through the climbing of the arc roots, since the tendency to climb is offset by the forward motion of the wire. The explanation given by Lucas et al. seems to be realistic, since on one hand, higher current would demand more oxides on the wire surface for cathode emission; on the other hand, faster WFS would delivery more oxides per unit of time.

Considering the abovementioned features of DCEN, one could say that DCEN GMAW is a promising technique, able of increasing the production capacity of the process without special equipment or wires, as long as high current intensity and a proper shielding gas are employed. However, there is still a demand for more information especially on gas composition and parameter settings. Therefore, the objective of this work was to explore further the use of DCEN in GMAW, aiming applications where high production with no sophisticated power sources are desired (low investments). The target of the study was a prelude to the development and optimization of shielding gas mixtures for welding specific joint. The methodological differentials to the ones shown in current literature are a bead geometric comparison with the conventional DCEP GMAW at a same bead volume (bead shape compared under the same filled groove, as demanded in production) and at the shortest arc length without short-circuiting (appropriate setting to each shielding gases). Higher emphasis on bead geometry and spatter generation was also targeted, as much as physics related explanation of the involved phenomenon, as support for the further developments. 


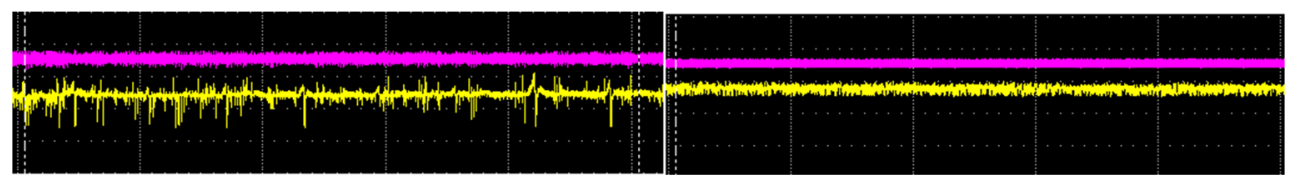

Fig. 1 Oscillograms of current (trace above) and voltage (trace below) to illustrate the criterion for trimming the wire feed speed to the target value: on the left, still presenting short-circuiting; on the right, free of short-circuiting after reducing slightly (trimming) the wire feed speed

\section{Methodology and experimental procedures}

Conditions to favor metal transfer in negative polarity were planned. The key aspect was to work in spray metal transfer, which is reachable by a proper choice of the shielding gas and current level. In this work, two series of Ar-based shielding gases were chosen, binary blended with increasing contents of $\mathrm{CO}_{2}(2,8$, and $18 \%)$ and $\mathrm{O}_{2}$ ( 2 and $6.5 \%$ ). These blends present oxidizing potentials needed to assist field electron emission from nonthermionic workpiece materials [7]. However, the highest content of oxidizing gas in the Ar-based blends was limited by the spray transfer maintenance. The gases were supplied $(22 \mathrm{l} / \mathrm{min})$ from commercial bottles, except the $6.5 \%$ of $\mathrm{O}_{2}$ mixture, which were blended using a commercial gas mixer. With limited capacity at that moment, the composition certification of the gas mixer was done by experimental observation.

Still favoring spray transfer, and considering that current level is the most important governing parameter of metal transfer, an intentional current level of $270 \mathrm{~A}$, above the expected transition current in positive polarity to all blends, was targeted at all welds. To reach this value, an electronic inverter power source and a matching wire feeder were used. To avoid oscillation of current around the target value and production of interchangeable metal transfer [17], the power source was set to operate in

Table 1 Matrix of welding experimental conditions

\begin{tabular}{llllll}
\hline $\begin{array}{l}\text { Run } \\
(*)\end{array}$ & $\begin{array}{l}\text { Shielding } \\
\text { gas }\end{array}$ & Polarity & $\begin{array}{l}\text { Current } \\
(\mathrm{A})\end{array}$ & $\begin{array}{l}\text { WFS } \\
(\mathrm{m} / \mathrm{min})\end{array}$ & $\begin{array}{l}\text { TS } \\
(\mathrm{cm} / \mathrm{min})\end{array}$ \\
\hline 9 & $2 \% \mathrm{CO} 2-\mathrm{Ar}$ & DCEN & 270 & 15.9 & 48 \\
10 & $2 \% \mathrm{CO} 2-\mathrm{Ar}$ & DCEP & 270 & 13.1 & 40 \\
1 & $8 \% \mathrm{CO} 2-\mathrm{Ar}$ & DCEN & 270 & 16.6 & 50 \\
3 & $8 \% \mathrm{CO} 2-\mathrm{Ar}$ & DCEP & 270 & 13.0 & 39 \\
5 & $18 \% \mathrm{CO} 2-\mathrm{Ar}$ & DCEN & 270 & 16.3 & 49 \\
6 & $18 \% \mathrm{CO} 2-\mathrm{Ar}$ & DCEP & 270 & 13.5 & 41 \\
8 & $2 \% \mathrm{O} 2-\mathrm{Ar}$ & DCEP & 270 & 12.5 & 38 \\
7 & $2 \% \mathrm{O} 2-\mathrm{Ar}$ & DCEN & 270 & 16.0 & 48 \\
12 & $6.5 \% \mathrm{O} 2-\mathrm{Ar}$ & DCEN & 270 & 17.4 & 53 \\
13 & $6.5 \% \mathrm{O} 2-\mathrm{Ar}$ & DCEP & 270 & 13.2 & 40 \\
2 & $8 \% \mathrm{CO} 2-\mathrm{Ar}$ & DCEP & 270 & 13.0 & 50 \\
4 & $18 \% \mathrm{CO} 2-\mathrm{Ar}$ & DCEP & 270 & 13.5 & 50 \\
\hline
\end{tabular}

*Random order of execution as indicated by the run number a constant current mode. Another advantage of using constant current mode rather than constant voltage mode is the fact that voltage becomes free. As voltage is much more sensitive to transients than current, this electrical signal was used to analyze the arc behavior under different polarities.

The assessment of the performance of the GMAW DCEN was carried out by comparison with the traditional process with positive polarity (GMAW DCEP). Accordingly, in addition to the current level, some other restraints were defined and applied in the experiments:

- Same wire (material and composition);

- Same torch and contact tip-to-work distance;

- Same test plates (material and dimensions);

- Same so-called "arc length" (see details in a following paragraph);

- Same deposition rate per unit of weld bead length.

The responses used to compare the effects of the polarity and shielding gases on the process performance in both polarities were:

- Fusion rate (wire mass per unit of time), i.e., production capacity;

- Deposited cross-section areas;

- Arc energy, arc length, and arc voltage;

- Fusion cross-section areas (deposited + fusion $=$ bead cross-section area);

- Heat affected zone cross-section area (excluding the fusion area);

- Bead finish;

- Bead convexity.

For this stage, structural carbon steels were the application target. An AWS ER70S-6 class wire, $1.0 \mathrm{~mm}$ diameter, was selected. The wire diameter was chosen based on the fact that globular and short-circuit transfers were aimed to be avoided. A long contact tip-to-work distance (CTWD) was set as $23 \mathrm{~mm}$, to both intensify the high production characteristic of the study and to prevent burn back due to arc climbing, which is expected during DCEN. Test plates were prepared with dimensions of $300 \times 100 \times 10 \mathrm{~mm}$ from plain carbon steel plates. The thickness was chosen to avoid disguising the effect of the gas and polarity by an impaired heat conduction. 
Fig. 2 Sequence of the image processing for arc length measurement: a frame before and after image processing and the arbitrary definition of arc length
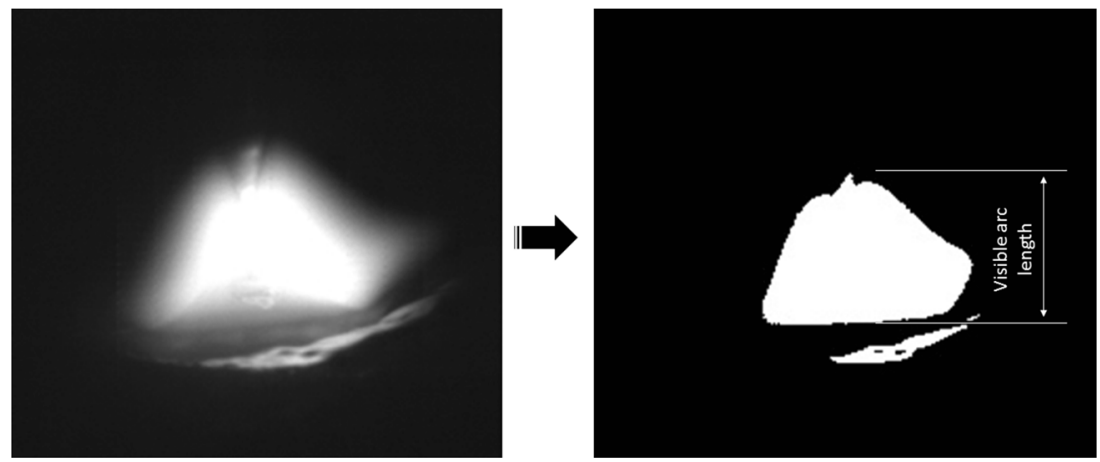

Arc length is an important parameter in welding (as important as current intensity), mainly concerning metal transfer and bead formation. For the sake of comparison, the arc length must be the same for all shielding gases. On one hand, arc length is easily tuned by the WFS when using constant current operation mode: the faster the WFS, the shorter the arc. On the other hand, despite the intrinsic difficulties to define quantitatively an arc length [5], the negative polarity tends to have the arc root well above the droplet formation area [20]. Therefore, to compare arc length in such different conditions is not feasible. In addition, it is important to remember that for a given setting (current and CTWD), changes in the polarity and/or in the shielding gas lead to dissimilar fusion rates (which is quantified by the WFS). Therefore, instead of using the arc length as one of the restraints, as listed above, it was decided to keep the wire tip (with droplets) to pool surface distance as short as possible for each combination, but not too short to make predominant the contact between the wire tip (droplet) and the pool before droplet detachment. Some spatter, nevertheless, would still be possible, but from other reasons rather than short-circuit transfer.

The criterion used in this work to replace arc length measurement and allow the comparisons (at the same wire tip to pool surface distance) states that all welds would be carried out with WFS as high as possible, yet without short-circuiting.
To attend the criterion, a trial and error approach was applied to find the appropriate WFS setting value for each combination of polarity-shielding gas. The wire speed was increased up to have noticeable (by both emitting noises and appearance of the voltage traces) short circuits (yet not stubbing). Then, the WFS was progressively trimmed to a slower value up to a setting that a smooth voltage trace was reached. Accordingly, the control of this short-circuit free condition was made with the aid of the voltage traces (Fig. 1).

A last condition used to compare the behavior of different combinations was to keep the same deposition rate per unit of bead length (i.e., the same deposited bead volume or the same deposited cross-section area). This is possible by keeping constant the ratio WFS and travel speed (TS). In this case was applied WFS/TS $=33$, resulting in a deposition rate of $203 \pm$ $1 \mathrm{~g} / \mathrm{m}$, if spattering (material losses) are not considered. A deposited cross-section area $\left(\mathrm{A}_{\mathrm{dep}}\right)$ of approximately $25 \mathrm{~mm}^{2}$ reached from using this ratio was defined as adequate. In this approach, the welding energy will be varied, which is a potential disadvantage, since this in turn will influence bead formation and the result discussions. On the other hand, by keeping welding energy constant (same travel speed, regardless WFS), $A_{\text {dep }}$ would be different for all welding conditions, which also would affect the bead formation. In fact, it is not possible to keep all variables at a constant value, when

Fig. 3 Experimental rig to carry out the weldments

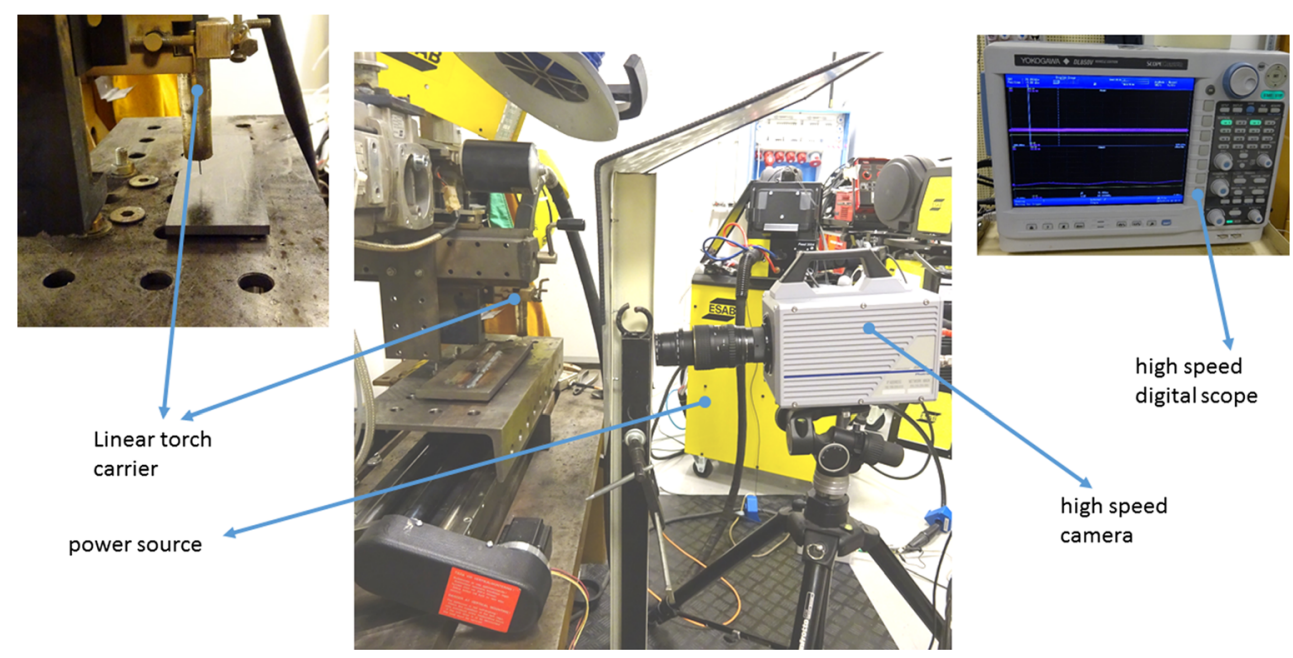




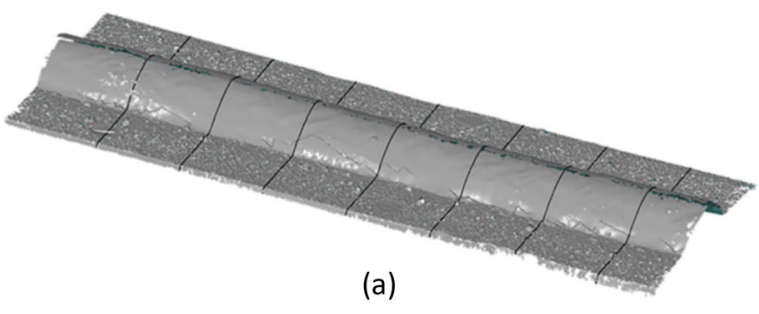

(a)

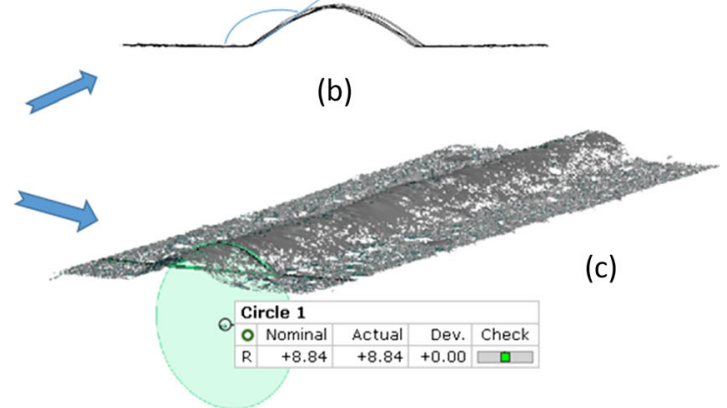

included angle at the bead toe. $\mathbf{c}$ The inscribed circle in one of the cross sections and the measured radius

monitored by a high-speed digital signal recorder, at a rate of $1 \mathrm{MHz}$ and 16 bit. Through the data logger software, the traces of both electrical signals and the mean values of them were raised. Synchronization of the electrical signals and the camera frames was also possible by working at the same frame and acquisition rates and trigging both devices at the same time. The actual mean wire feed speed, in turn, was measured by the welding power source display (calibrated). Figure 3 presents details of the experimental rig.

Wire fusion rate, bead finish, bead geometry, and bead convexity were defined as responses for comparison purposes, taking into account the potential and expected influence of the polarity on these characteristics. The fusion rate (wire mass per unit of time) was quantified by the WFS set to keep the same current, whereas the bead finish was qualified visually. Three cross sections of each bead were randomly selected and metallographically prepared (polished and etched by $5 \%$ Nital solution) and the average widths, reinforcements, penetrations, and heat affected zone (HAZ) areas were determined with the aid of a digital metallographic stereoscope. A commercial structured light 3-D scanning was employed for convexity evaluations. Bead convexity is conventionally determined by a ratio between bead width and reinforcement height (the lower the ratio, the more convex). However, two
Fig. 5 The correlation among the ratio bead width-reinforcement height, the inscribed circle in the deposited cross-section area and the included angle at the bead toe for the experiments of Table 1

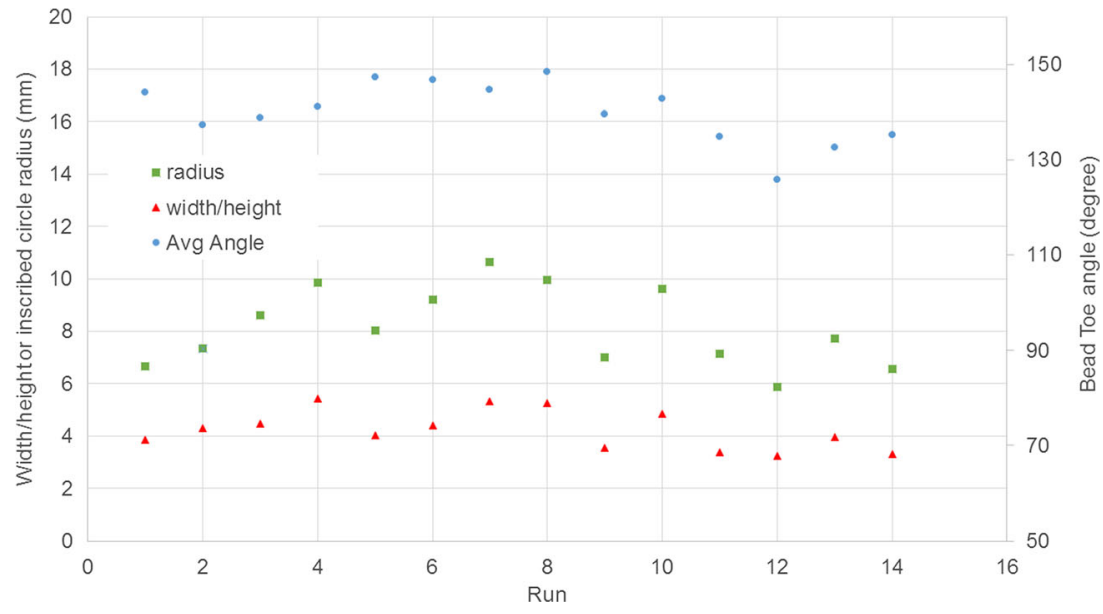


Fig. 6 Effect of the shielding gas and polarity on fusion rate (assessed by the WFS), at the same target current (270 A), bead volume, and distance droplet-pool surface (one run per welding gaspolarity combination)

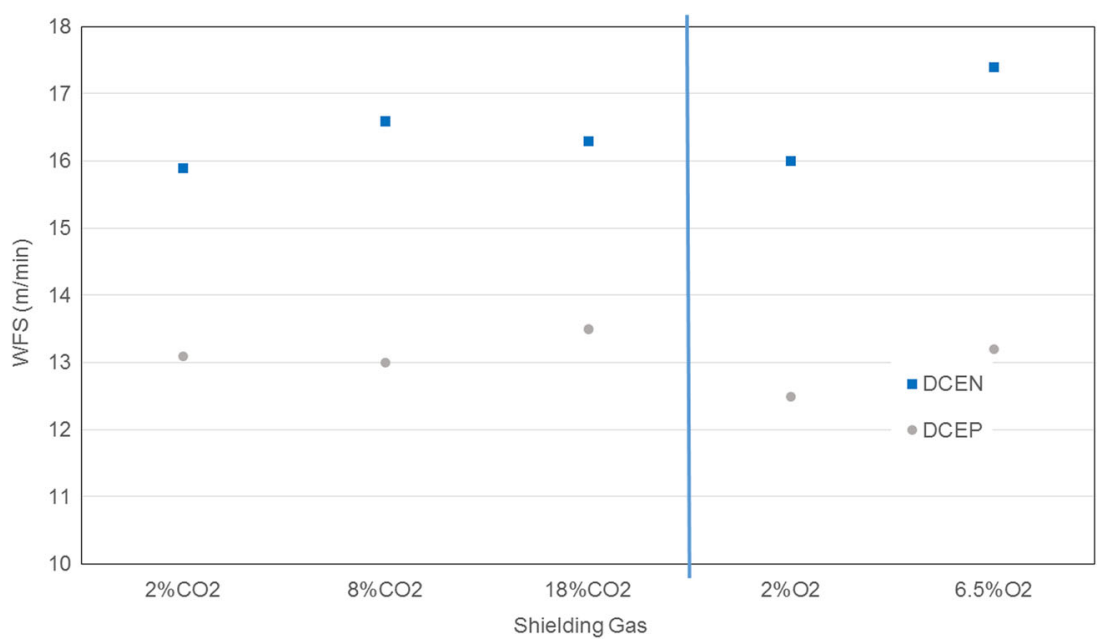

\section{Results}

approaches were tried in this study by using the 3-D scan on a bead portion centrally located, of approximately $80 \mathrm{~mm}$ long: (a) angle at the bead toes (the smaller the angles, the more convex); (b) inscribed circle in the deposited cross-section area, taking as references the upmost point and the points at the interceptions bead-plate (the shorter the radius, the more convex). The objective was to replace the traditional parameter bead width/reinforcement height by one parameter more related to the bead contour and its interception with the plate surface. Figure 4 illustrates both procedures.

The two approaches used to assess the bead convexity to the conventional bead width/reinforcement height factor are compared in Fig. 5. The radius showed to be highly correlated to this traditionally used factor, whereas the included angle showed a poorer correlation. Angle seems to be more sensitive to punctual shape irregularities, whereas the radius represents better the tendencies. Therefore, according to this work objective, the radius of the inscribed circle in the deposited crosssection area was hereafter used as a means of quantifying bead convexity.

A higher production capacity potentially allows producing the same bead volume at a faster speed (higher productivity - shorter weld time, lower gas consumption, less manpower costs). Figure 6 shows that DCEN operates with much faster WFS (higher melting rate) than DCEP (an increase of 21 to $32 \%$ ) at the same current level, regardless the shielding gas. In positive polarity and with blends with $\mathrm{O}_{2}$, there is a tendency of the fusion rate to increase as the content of the oxidizing gas become higher. The highest WFS was reached with $\mathrm{Ar}+6.5 \% \mathrm{O}_{2}$. At first view, DCEN is prone to higher production. However, it is important to point out that the spattering level with DCEN is, in general, higher than with DCEP. Therefore, DCEN presented lower deposited cross-section areas $\left(A_{\text {dep }}\right)$ than expected (even though WFS/TS had been kept constant). As illustrated in Fig. 7, the deviation between $\mathrm{A}_{\text {dep }}$ with both DCEP and DCEN ranged from 7 to $23 \%$ (the higher the spatter generation, the wider the
Fig. 7 Effect of the shielding gas and polarity on bead-on-plate deposited cross-section area, at the same target current (270 A), bead volume and distance droplet-pool surface (average of three cross sections)

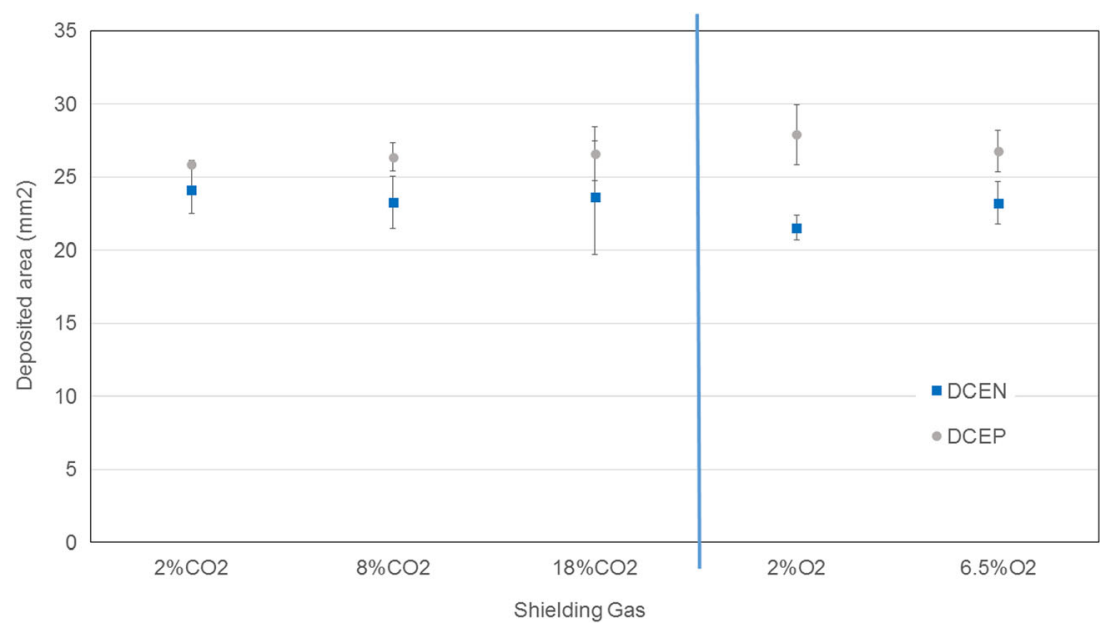


Fig. 8 Effect of the shielding gas and polarity on visible arc length (averages of seven frames from a same experimental run), at the same target current $(270 \mathrm{~A})$, bead volume, and distance droplet-pool surface

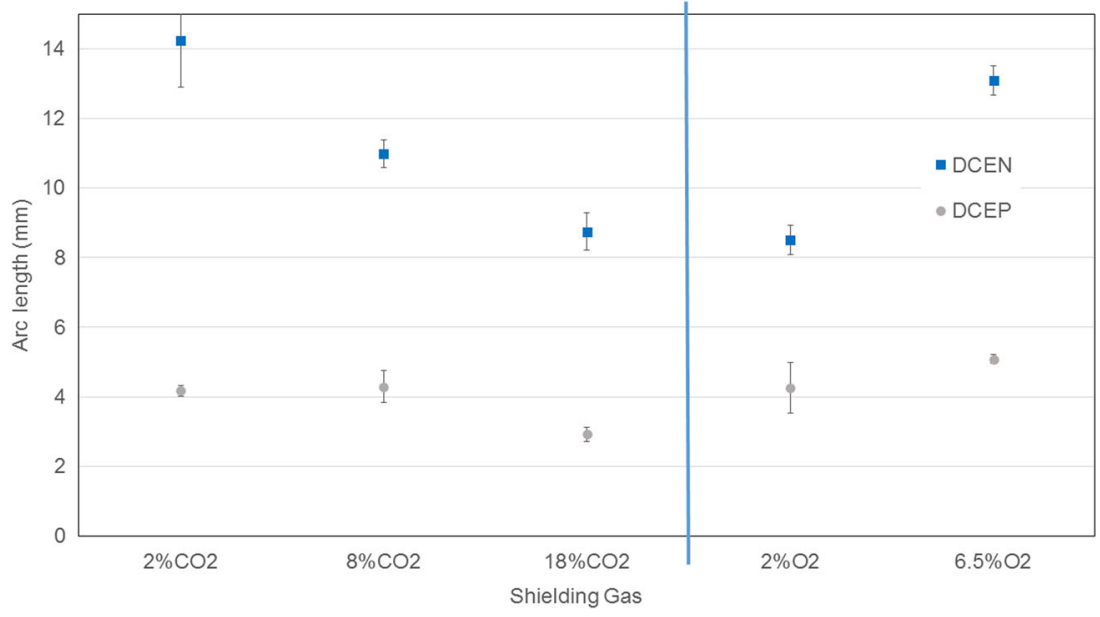

deviation). A simple TS correction calculation compensates for spattering and allow the DCEN condition to reach the same $A_{\text {dep }}$ as with DCEP. The results showed that the favorable characteristic of higher production capacity of DCEN disappear when spattering generation is high (the fusion rate is higher, but not the deposition rate and, consequently TS). However, this same calculation showed that for conditions of low spattering, this favorable characteristic would persist (cases of $2 \% \mathrm{CO}_{2}$ and $\left.6.5 \% \mathrm{O}_{2}\right)$.

As seen in Fig. 8, the increase of the $\mathrm{CO}_{2}$ content decreased the arc length with DCEN, although no distinguished effect is observed with DCEP. It is important to remember that arc length in DCEN climbs the wire looking for oxides for electron field emission, as pointed out by Norrish [12], Lucas et al. [9], Souza et al. [20], amongst others. That is, if the wire tip becomes slenderer, arc heating has more influence on the wire melting [8]. This phenomenon does not happen in DCEP, in which the field emission happens on the plate surface. Figure 9 uses experimental results to illustrate this phenomenon, from which one can see that the droplet detachment with DCEP takes place close to the arc root. In its own way, the

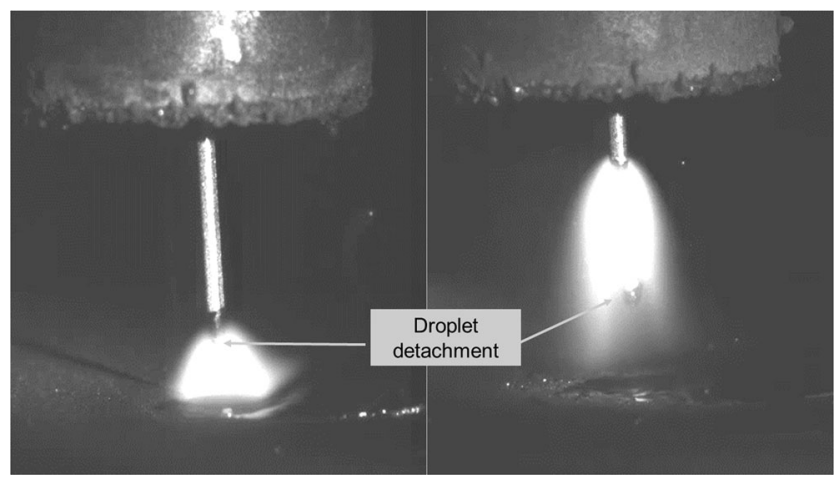

Fig. 9 Typical visible arc lengths with different polarities, DCEP on the left and DCEN on the right (same CTWD $=23 \mathrm{~mm}, \mathrm{Ar}+8 \% \mathrm{CO}_{2}, 270 \mathrm{~A}$, same target bead volume and distance droplet-pool surface) droplet detachment with DCEN occurs in the middle of the arc column, having a wire portion surrounded by the arc from the detachment point up to the region of the highest arc-wire connection. This climbing effect justify the above-appointed higher wire melting rate (assessed by the WFS) with DCEN. The reduction of the arc length when the $\mathrm{CO}_{2}$ content increases in the shielding gas is also justified based on the same climbing characteristic. The increase of $\mathrm{O}_{2}$ in the shielding gas does not present the same trends, showing an increase of current from the blend $\mathrm{Ar}+2 \% \mathrm{O}_{2}$ to $5 \% \mathrm{O}_{2}$ in DCEN. One must remember that arc length in this work is measured by the visible arc length, not necessarily the actual arc length.

The analysis can be complemented observing the effect of the gas-polarity combination on fusion zone (FZ) and on net heat affected zone $\left(\mathrm{HAZ}_{\mathrm{net}}\right)$ areas, factors that would give a better sense of heat input. In this work, net values of heat affected zone cross-section areas were calculated by subtracting the FZ areas and the $\mathrm{A}_{\text {dep }}$ from the total metallurgically affected areas. Figure 10 shows that the respective areas with DCEN are smaller, meaning that less heat was transferred to the plate or generated on the plate surface (cathodic or anodic areas). FZ and $\mathrm{HAZ}_{\text {net }}$ present different trends. It is clear the increase of heat transferred to the plate used to melt the base metal with higher content of $\mathrm{CO}_{2}$, yet not to enlarge the $\mathrm{HAZ}_{\text {net }}$ (with both polarities). It suggests an increase of melting efficiency with higher $\mathrm{CO}_{2}$ contents, supported by the shortening of the arc (Fig. 8). $\mathrm{HAZ}_{\text {net }}$ crosssection area is influenced by polarity yet not by the shielding gas composition, when $\mathrm{CO}_{2}$ is used in the shielding gas. However, an increase of $\mathrm{O}_{2}$ content in the shielding gas reduced the HAZ ${ }_{\text {net }}$, with DCEP and DCEN. The likely reason would be that from a higher oxidizing potential of the shielding gas, one would expect less heat generated on the plate when the weld pool is emitting electrons (DCEP). It is important to say that one can also expect that the wider the HAZ, the more heat was input into the plate. These results and analysis confirm that by welding with DCEN less heat is 

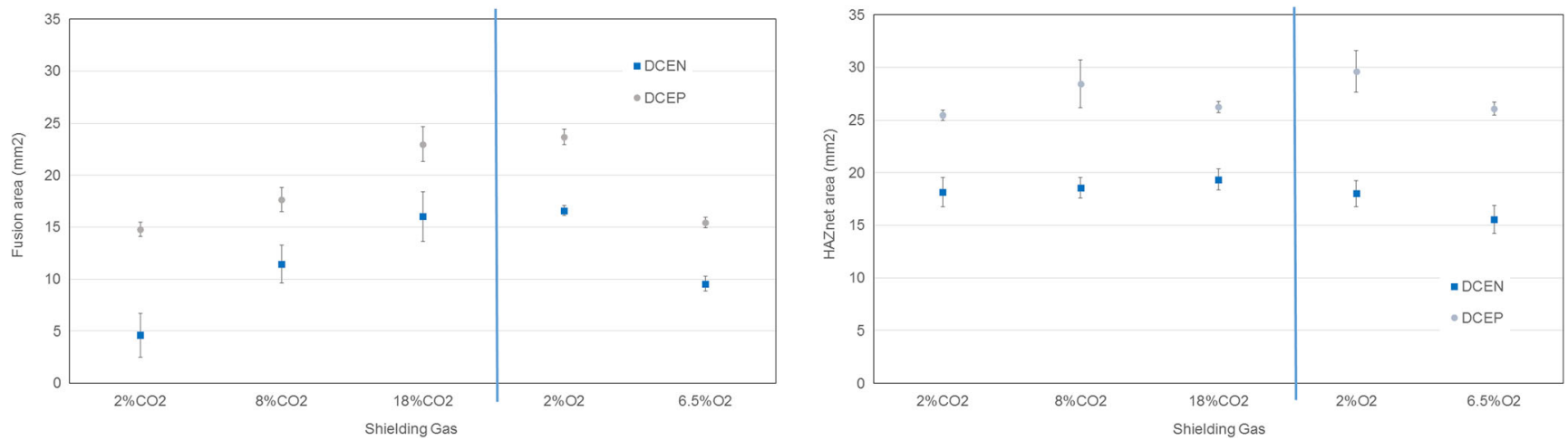

Fig. 10 Effect of the shielding gas and polarity on the fusion $(F Z)$ and net heat affected zone $\left(H A Z_{\text {net }}\right)$ cross-section areas, where fusion area $=$ bead deposited cross-section areas, at the same target current $(270 \mathrm{~A})$, bead volume and distance droplet-pool surface

imposed to the plate for the same mean current and arc energy. This is possible due to less heat generated at the pool surface with DCEN than with DCEP.

The analysis of the polarity-shielding gas combination effect on the bead profile and finishing was developed based on Figs. 11 to 13. As seen in Fig. 11, the beads show unquestionable better finish with DCEP, almost free of spatter. The increase of $\mathrm{CO}_{2}$ deteriorates the bead finish in both polarities. Dark smutting (brownish oxides) increases with the oxidizing potential of the shielding blend, yet DCEN (longer arc) remarkably favored smutting. With DCEN, spattering gets unacceptable for high content of $\mathrm{CO}_{2}$, as expected from the literature review. Nevertheless, the finish and reduction of spattering improved with $\mathrm{O}_{2}$ replacing $\mathrm{CO}_{2}$ in the shielding gas in the negative polarity. The best condition with DCEN seems to be shielded with $\mathrm{Ar}+6.5 \% \mathrm{O}_{2}$.

These results are in some agreement with Lucas et al.'s [9] findings. In terms of arc stability, these authors considered that the Ar-based bends with addition of $2 \% \mathrm{O}_{2}, 5 \% \mathrm{O}_{2}$ and $5 \% \mathrm{CO}_{2}$ are suitable shielding gases for DCEN GMAW. It is important to point out that in the present results a blend $\mathrm{Ar}+8 \% \mathrm{CO}_{2}$ had already presented high spattering level. Norrish [12] also found good arc stability and bead formation with $\mathrm{Ar}+$ $5 \% \mathrm{O}_{2}$; stable arcs were obtained at wire feed speeds of 9$17 \mathrm{~m} / \mathrm{min}$ (1-mm wire), metal transfer was coaxial with the wire and a globular-to-spray transition occurred at $170 \mathrm{~A}$. The present results and the cited information from literature suggest that the shielding gas composition plays more important role when DCEN is intended to be used.

One expected outcome of the DCEN usage in GMAW would be a lower penetration when the same current level is used. As seen in Fig. 12, this trend is observed (from -1 to $-3 \mathrm{~mm}$, taking an average $4 \mathrm{~mm}$ deep bead as reference). This figure also suggests that the effect of the shielding gas is marginal. However, one can notice in Fig. 13 that the higher penetration with DCEP is characterized by finger-like shape (side bead penetration is not significantly higher). DCEN tends to a soup plate shape. The finger-like bead profile in spray arc GMAW is credited to the momentum of the droplets hitting the weld pool [16]. Changes in the arc shape and metal transfer mode in DCEN when compared to in DCEP would justify this difference. One support for this reasoning is the fact that penetration difference between DCEP and DCEN shortens, even slightly, with increasing $\mathrm{O}_{2}$ content in the
Fig. 11 Beads appearance after welding with DCEP, on the left, and DCEN, on the right, and different shielding gas compositions, at the same target current $(270 \mathrm{~A})$, bead volume and distance droplet-pool surface

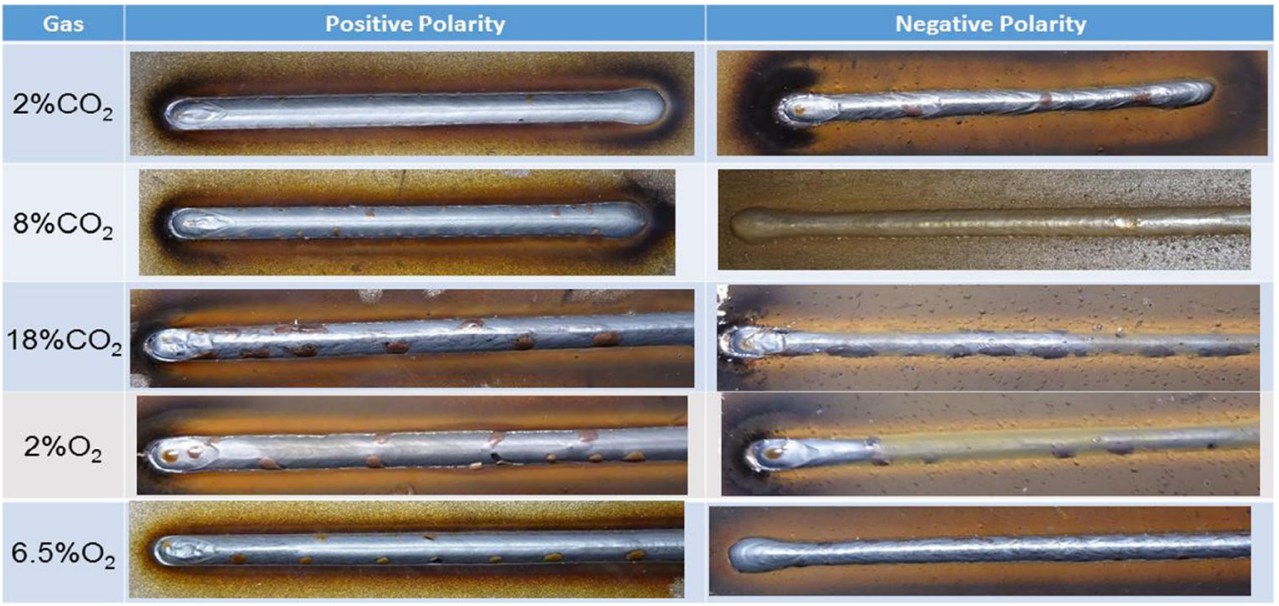


Fig. 12 Effect of the shielding gas and polarity on bead-on-plate maximum penetration, at the same target current (270 A), bead volume and distance droplet-pool surface (average of three cross sections)

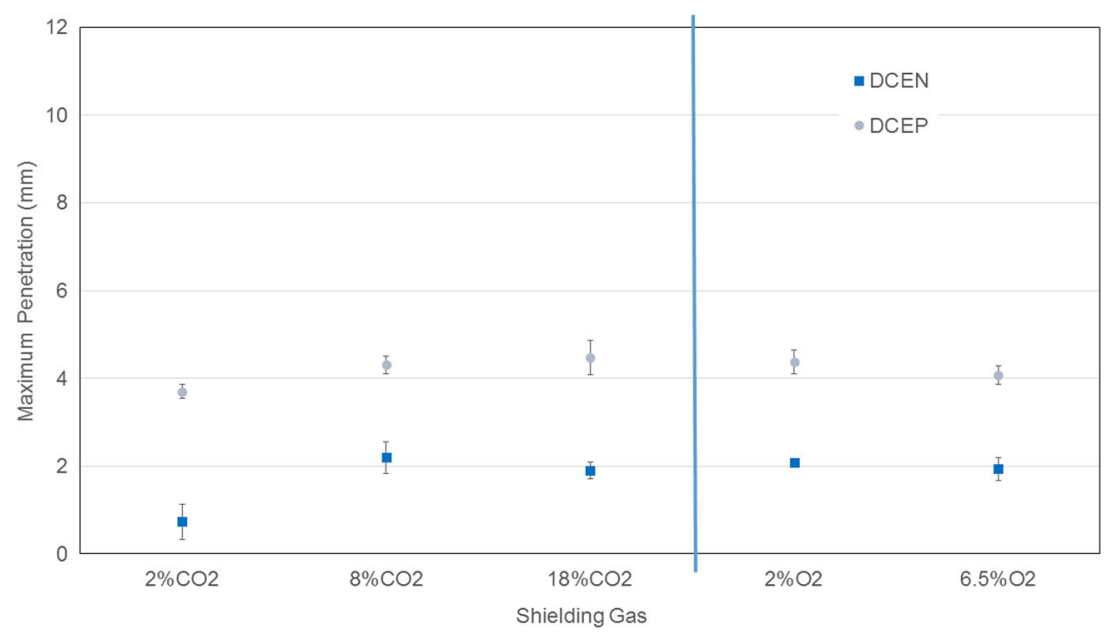

shielding gas, making the metal transfer smoother (less spattering).

It is important to point out that penetration is due to a complex inter-correlation of variables and mechanisms (mechanical, thermal, and electromagnetic) that governs the weld bead formation, as explained by Silva and Scotti [19]. Numerical simulation would be a useful tool to uncover the fundamental governing factors on bead geometry formation when GTAW DCEN and DCEP are compared, although simulations dealing with GMAW DCEN was not found in current literature. According to, e.g., Edstorp [4], since the state of the related quantities is strongly influenced by phenomena such as arc and droplet impingement, non-isothermal phase change, surface tension, Marangoni forces, and Lorentz forces, much effort is necessary for modeling the phenomenon. Mougenot et al. [10] stated that, when surface deformation is assumed negligible, the weld pool movement is driven by four forces: the Marangoni (due to the of surface tension gradient); the drag force (due to the interaction of the plasma velocity with the surface); the Laplace; and buoyancy. As conclusion, they highlighted the influence of the parameters used in the Marangoni formulation. It is important to state that Mougenot et al. [10] investigated autogenous TIG modeling.

The arc properties and thus the energy transferred to the work piece, in turn, depends on various parameters such as the nature of the plasma gas, the arc length, the angle of the tungsten electrode, the metal vapor [11], the arc attachment on the electrode (Javidi [18]), the polarity, as the arc interaction with
Fig. 13 Bead cross sections after welding with DCEP, on the left, and DCEN, on the right, and different shielding gas compositions, at the same target current (270 A), bead volume and distance droplet-pool surface

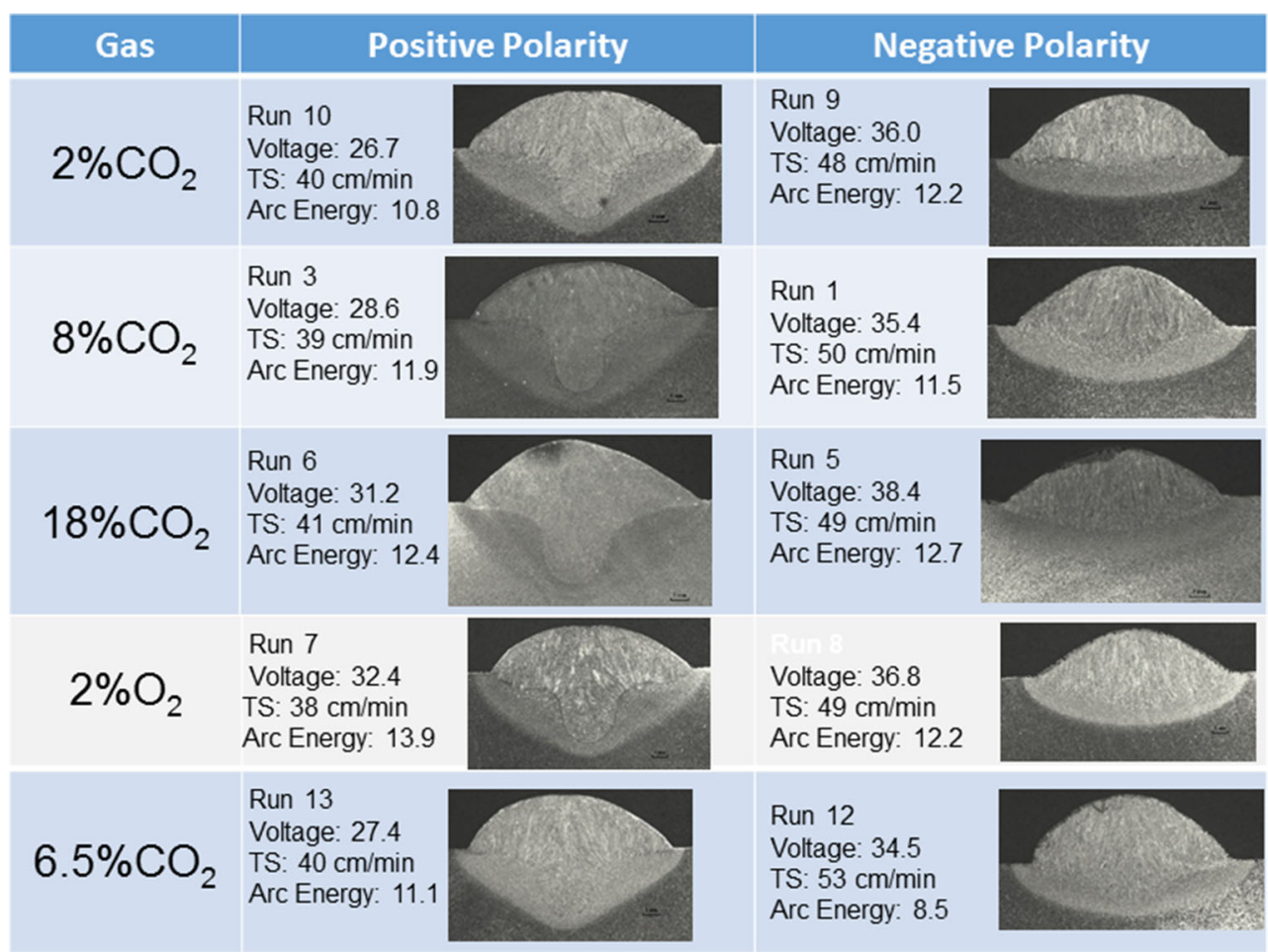


Fig. 14 Effect of the shielding gas and polarity on bead convexity (assessed by the radius of inscribed circle in the deposited cross-section area), at the same target current (270 A), bead volume and distance droplet-pool surface (average of three cross sections)

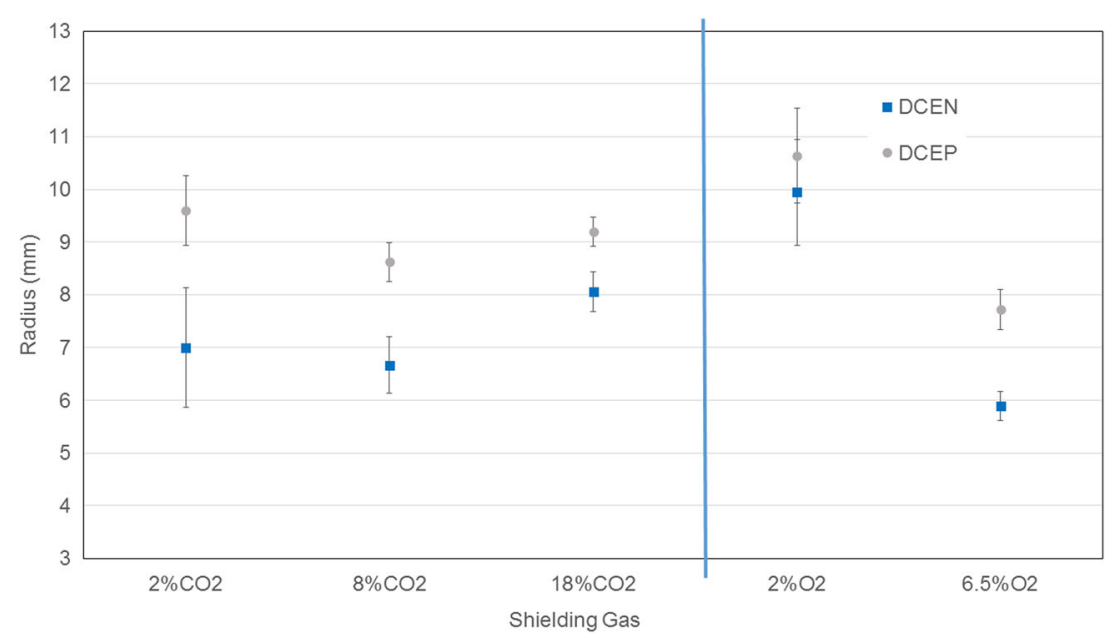

the transferred metal (as shown in the context of GMAW by [6]). The properties of the pool also depend on other parameters such as the nature of the metal, its vaporization, as well as surface deformation (see [14], and [15]), and metal transfer.

As seen, to describe bead formation is still a challenge for the arc welding technology and this is the reason for having bead formation explanation out of this work scope. However, from the operational level, the authors believe that, besides the influence of the droplet momentum above stated, one could mention among the governing operational welding parameters the current intensity, travel speed, arc length, shielding gas composition, metal vapor, and polarity. For instance, neither arc length (Fig. 8) or fused area (related to heat input, Fig. 10) can explain alone the maximum penetration trends shown in Fig. 12.

Finally, the last aspect to be analyzed is bead convexity. As discussed earlier, the parameter was assessed by using the radius of inscribed circle in the deposited cross-section area. As seen in Fig. 14, DCEN is prone to more convex beads (smaller radius). With $\mathrm{CO}_{2}$ as shielding gas, there is no trend. However, with $\mathrm{O}_{2}$, the higher its content the more convex turns the bead. However, as seen in Fig. 13, all the beads presented acceptable profiles and low stress concentration factor at the bead toe.

\section{Conclusions}

GMAW with negative polarity (DCEN) and spray transfer is feasible when using the right combination of shielding gas composition and current setting. For the same mean current and arc energy, less heat input with DCEN than DCEP is confirmed. An Ar-based blend with a percentage of around $6.5 \%$ of $\mathrm{O}_{2}$ seems to reach acceptable bead finishing, bead geometry, and spattering level, yet keeping a higher deposition rate. The higher production capacity and the lower heat input compensates for the operational impairing of the negative polarity use (higher spattering, shallower penetration and not so nice bead finishing).

However, further studies are demanded to lead this operational approach to the factory floor. Arc length, which is longer with DCEN than with DCEP, seems to be a critical issue and synergic lines are demanded to keep the right arc length during welding. It has not been demonstrated by the work if constant current power source is demanded, but it seems that this type of static characteristic keeps the arc more stable. Further work is also demanded to certify if the penetration behavior of DCEN in this shielding gas-polarity combination can be sustained in a grooved joint, since all tests here were bead-on-plate. A refinement of the content of $\mathrm{O}_{2}$ in the Ar-based blend is also desirable for reaching the best gas composition for this process version.

Acknowledgements The authors of this work would like to thank Esab $\mathrm{AB}$ and University West for the laboratory facilities. They acknowledge the financial support from the Swedish Agency for Economic and Regional Growth, under grant 20200328, and Region Västra Götaland, under grant RUN 612-0254-15. These grants support the project MAPLAB. They also thank the colleague Dr. Isabelle Choquet, for the inputs on bead formation governing parameters.

\section{Compliance with ethical standards}

Conflicts of interest The authors declare that they have no conflict of interest.

Open Access This article is distributed under the terms of the Creative Commons Attribution 4.0 International License (http:// creativecommons.org/licenses/by/4.0/), which permits unrestricted use, distribution, and reproduction in any medium, provided you give appropriate credit to the original author(s) and the source, provide a link to the Creative Commons license, and indicate if changes were made.

\section{References}

1. Arif N, Chung H (Sep 2014) Alternating current-gas metal arc welding for application to thin sheets. J Mater Process Technol 214(9):1828-1837. https://doi.org/10.1016/j.jmatprotec.2014.03.034 
2. AWS (1991) Welding Processes: Welding Handbook - Vol 2, 8th Edn. AWS, p 119: ISBN: 0-87171-354.3

3. Dutra JC, Gonçalves E, Silva RH, Savi BM, Marques C, Alarcon OE (2016) New methodology for AC-pulsed GMAW parameterization applied to aluminum shipbuilding. J Braz Soc Mech Sci Eng 38(1):99-107. https://doi.org/10.1007/s40430-015-0351-3

4. Edstorp M (2008) Weld pool simulations, PhD. Thesis, Chalmers University of Technology and University of Gothenburg, Department of Mathematical Sciences. NO:19, ISSN 1652-9715, http://www.math.chalmers.se/Math/Research/Preprints/2008/19.pdf

5. Egerland S (2015) A contribution to arc length discussion. Soldag Insp 20(3):367-380. https://doi.org/10.1590/0104-9224/SI2004.06

6. Hu J, Tsai HL (2007) Heat and mass transfer in gas metal arc welding - part I: the arc. Int J Heat Mass Transf 50(5-6):833-846. https://doi.org/10.1016/j.ijheatmasstransfer.2006.08.025

7. Jönsson PG, Murphy AB, Szekely J (1995) The influence of oxygen additions on argon-shielded GMAW processes. Weld J AWS 74(2):48s-58s

8. Kim K, Chung H (2017) Wire melting rate of alternating current gas metal arc welding. Int J Adv Manuf Technol 90(5-8):1253-1263. https://doi.org/10.1007/s00170-016-9384-8

9. Lucas W, Street JA, Watkins PVC (1978) Solid wire AC MIG welding. Welding Res Int 8(2):102-127

10. Mougenot J, Gonzales J-J, Freton P, Masquère M (2013) Plasmaweld pool interaction in tungsten inert gas configuration. J Phys D Appl Phys 46(13) 14 p. https://doi.org/10.1088/0022-3727/46/13/ 135206

11. Murphy AB (2010) The effect of metal vapor in arc welding. J Phys D Appl Phys 43(43) 31 p. https://doi.org/10.1088/0022-3727/43/ 43/434001434001

12. Norrish J (1974) High deposition MIG welding with electrode negative polarity. Proc. Conf. "Advances in Welding Processes", vol 16. TWI paper, Harrogate, pp $121-128$
13. Park HJ, Kim DC, Kang MJ, Rhee S (2013) The arc phenomenon by the characteristic of EN ratio in AC pulse GMAW. Int J Adv Manuf Technol 66(5-8):867-875. https://doi.org/10.1007/s00170012-4371-1

14. Pitscheneder W, Debroy T, Mundra K (1996) Role of sulfur and processing variables on the temporal evolution of weld pool geometry during multikilowatt laser beam welding of steels. Welding $\mathrm{J}$ 75(3):71.s-80.s

15. Saldi ZS (2012) Marangoni driven free surface flows in liquid weld pools 159 p. Doctoral Thesis, Delft University of Technology, Fac Appl Sci. https://doi.org/10.4233/uuid:8401374b-9e9c-4d25-86b7fc 445 ec $73 \mathrm{~d} 27$

16. Scotti A, Rodrigues CEAL (2009) Determination of momentum as a mean of quantifying the mechanical energy delivered by droplets during MIG/MAG welding. Eur Phys J Appl Phys 45(1):11201. https://oi.org/10.1051/epjap:2008196

17. Scotti A, Ponomarev V, Lucas W (2014) Interchangeable metal transfer phenomenon in GMA welding: features, mechanisms, classification. J Mater Process Technol 214(11):2488-2496. https://doi. org/10.1016/j.jmatprotec.2014.05.022

18. Shirvan AJ, Choquet I, Nilsson H (2016) Effect of cathode model on arc attachment for short high-intensity arc on a refractory cathode. J Phys D Appl Phys 49(48):17. https://doi.org/10.1088/00223727/49/48/485201

19. Silva DCC, Scotti A (2017) Using either mean or RMS values to represent current in modeling of arc welding bead geometries. J Mater Process Technol 240:382-387. https://doi.org/10.1016/j. jmatprotec.2016.10.008

20. Souza D, Resende AA, Scotti A (2010) A qualitative model to explain the polarity influence on the fusion rate in the MIG/MAG process. Weld Int 24(12):934-941. https://doi.org/10.1080/ 09507110903569032 